\title{
Propaganda, Non-Rational Means, and Civic Rhetoric*
}

\author{
Ishani MAITRA
}

Received: 04/08/2016

Final Version: 08/09/2016

BIBLID 0495-4548(2016)31:3p.313-327

DOI: $10.1387 /$ theoria.16859

ABSTRACT: This paper examines Jason Stanley's account of propaganda. I begin with an overview and some questions about the structure of that account. I then argue for two main conclusions. First, I argue that Stanley's account over-generalizes, by counting mere incompetent argumentation as propaganda. But this problem can be avoided, by emphasizing the role of emotions in effective propaganda more than Stanley does. In addition, I argue that more propaganda is democratically acceptable than Stanley allows. Focusing especially on sexual assault prevention campaigns, I show that propaganda can be acceptable even when it represents some in our communities as worthy of contempt.

Keywords: Propaganda, civic rhetoric, ideology, inequality, incompetence.

RESUMEN: Este artículo examina la teoría de la propaganda de Jason Stanley. Comienzo con una visión general y algunas cuestiones relativas a la estructura de esta teoría. A continuación, argumento en apoyo de dos conclusions principales. En primer lugar, argumento que la teoría de Stanley sobre-generaliza, al considerar como propaganda lo que es mera argumentación incompetente. Pero este problema puede evitarse si se enfatiza el papel de las emociones en la propaganda efectiva más de lo que Stanley lo permite. Adicionalmente, argumento que hay más propaganda democráticamente acceptable de la que Stanley permite. Centrándome en especial en las campañas de prevención contra la violencia sexual, muestro que la propaganda puede ser acceptable incluso cuando presenta a algunos miembros de nuestra comunidad como merecedores de desprecio.

Palabras clave: propaganda, retórica cívica, ideología, desigualdad, incompetencia.

\section{Introduction}

What is propaganda? How does it function? And when, and why, should we be concerned about its prevalence? These are just some of the questions that Jason Stanley tackles in his highly engaging new book, How Propaganda Works. This rich and wide-ranging work sounds a trenchant warning about the dangers of propaganda in liberal democracies, arguing that some kinds of propaganda pose an "existential threat" (11) to such societies. ${ }^{1}$

* Many thanks to Jason Stanley, Eric Swanson, Agustin Vicente, Brian Weatherson, and an audience at the American Philosophical Association's 2016 Pacific Division Meeting for helpful comments and discussion about the material covered in this paper.

1 Page numbers in parentheses refer to Stanley (2015). 
Stanley argues that much propaganda is deeply harmful. On his view, "harmful propaganda relies upon the existence of flawed ideologies present in a given society" (4). More specifically, the kind of propaganda in which Stanley is interested - what he calls 'demagoguery'- exploits flawed ideologies, and at the same time, strengthens them. These flawed ideologies, in turn, keep us from understanding the true nature of our social reality, and so degrade democratic deliberation. Thus, by helping to perpetuate flawed ideologies, propaganda threatens to undermine the very possibility of democracy.

Intriguingly, though, Stanley does not think that all propaganda is harmful in the manner just described. Rather, some propaganda - what he labels 'civic rhetoric' - can be positively beneficial, for it can help repair flawed ideologies. In so doing, civic rhetoric can in fact restore the possibility of democratic deliberation. Nevertheless, while acknowledging this possibility, Stanley also expresses broad discomfort with the idea of using propaganda to achieve any goal, no matter how worthy, in a democratic society.

Stanley's book is essential reading for those interested in harmful speech, democratic legitimacy, and ideology, among several related topics. In light of rising tides of hatred and xenophobia around the world, it's hard to imagine a more appropriate time to be discussing the questions raised here. The book is also remarkable in the way that it builds upon work from a disparate array of subfields within philosophy (including political philosophy, of course, but also philosophy of language, epistemology, feminist philosophy, philosophy of race, and more) as well as from neighboring fields like psychology and political science. It is a model for how ideas and tools from quite separate-seeming domains can be pulled together to address questions of broad public concern.

This paper will focus on two aspects of the book. The first is Stanley's view of what propaganda is (Chapters 2 and 3). I'll argue that his view over-generalizes in a crucial way, by counting as propaganda what should in fact be regarded as mere incompetence. I'll then consider some possible responses to this problem. A second aspect of the book that I'll also focus on is Stanley's account of when propaganda is permissible in a democratic society (Chapter 3). I'll argue that this account is far too restrictive, that propaganda has vital positive roles to play that go well beyond what Stanley allows. ${ }^{2}$

My discussion in this paper will largely be concerned with the first few chapters of the book. This means that I'll be leaving aside quite a lot that is of interest here. For example, I won't touch on Stanley's claim that the familiar distinction between at-issue and not-at-issue content can help us get a grip on how certain kinds of propaganda work (Chapter 4); and I'll only briefly discuss his argument that substantive inequalities of many kinds are democratically problematic because they allow harmful propaganda to flourish (Chapter 6). ${ }^{3}$ The paper thus makes no claim to covering all that is important (or controversial!) in the book.

The paper proceeds as follows. In the next section (\$2), I start with a brief overview of some of Stanley's main arguments. This overview will allow me to raise some questions about how those arguments fit together, and will also set up the discussion in the remainder of the paper. Sections 3 and 4 focus on Stanley's account of propaganda, specifically,

2 For some, the word 'propaganda' is a (strong) pejorative, so my talk of positive propaganda will seem nearly incoherent. For those readers, the interesting question is about civic rhetoric, specifically, about which representations should count as civic rhetoric, rather than propaganda.

3 See Swanson (forthcoming) for a very helpful discussion of the former claim, and Srinivasan (2016) for a rich commentary on the latter argument. 
his distinction between two kinds of propaganda. In $\$ 3$, I describe some virtues of that account, but also argue that the account over-generalizes. In $\$ 4$, I explore one way out of this problem of over-generalization, that I think (and will argue) is independently attractive. Next, in \$5, I turn to Stanley's view of civic rhetoric, and argue that it leaves out some propaganda that performs essential functions in societies like ours. Finally, in $\$ 6$, I briefly wrap up by emphasizing a theme that runs through my discussion.

\section{An overview}

As for any other notion, several distinct accounts of propaganda may be viable. Some may hew closely to the ordinary sense(s) of the word, while others might diverge from those ordinary sense(s) in order to better serve our theoretical purposes. (For discussion of the different kinds of projects theorists may engage in when theorizing about some notion, see Haslanger 2006 as well as other essays in her 2012.)

Stanley prefaces his account of propaganda with several examples of the phenomenon, including some from Victor Klemperer's landmark study The Language of the Third Reich. Of these examples, Stanley writes:

What emerges is the idea that demagogic contributions employ, whether intentionally or unintentionally, flawed ideologies to cut off rational deliberation and discussion. In characteristic cases, they do so by using the flawed ideologies to overwhelm affective states (47, emphasis added).

Stanley then distinguishes two accounts of propaganda that, though different from his preferred account, nonetheless attempt to capture something like the idea described in the passage above. The first of these - what he labels 'the classical sense of propaganda' - focuses on the use of propaganda to move people, or the state, to action. Typically, this is done by riling up emotions in a way that puts an end to rational debate. On this view, propaganda is "manipulation of the rational will to close off debate" (48, emphasis removed). ${ }^{4}$ A second account of propaganda - 'propaganda as biased speech', which Stanley attributes to Noam Chomsky - is less concerned with its role in producing action, and more with its role in structuring debate. On this view, propaganda is "speech that irrationally closes off certain options that should be considered" (49). Though these accounts are clearly different, they are united in taking propaganda to be opposed to rational debate (and action).

Stanley's preferred account echoes that last sentiment. He distinguishes two kinds of propaganda, characterized thus:

Supporting Propaganda: A contribution to public discourse that is presented as an embodiment of certain ideals, yet is of a kind that tends to increase the realization of those very ideals by either emotional or other nonrational means (53).

Undermining Propaganda: A contribution to public discourse that is presented as an embodiment of certain ideals, yet is of a kind that tends to erode those very ideals (53).

Propaganda of both kinds thus exemplifies, or embodies, certain ideals; these include political ideals, but also rational, scientific, economic, and other ideals. The two kinds then

4 I'll have a bit more to say about this conception in $\$ 4$. 
differ with respect to the effect they have on those ideals. As the label suggests, supporting propaganda tends to uphold those ideals; but it does so by "emotional or other nonrational means”. Undermining propaganda, by contrast, needn't work via non-rational means. But the success of undermining propaganda requires a different kind of failure of rationality, namely, the failure to notice the tension - or "a kind of contradiction" (53) - between the presented ideals and the effects of the propaganda.

Stanley offers a catalog of examples to illustrate both kinds of propaganda. But his primary interest is in the second kind, namely, undermining propaganda. A particularly striking illustration of this kind involves Ben Bernanke's use of the phrase 'fiscal cliff in early 2012 (83-86). ${ }^{5}$ Bernanke, then chairman of the Federal Reserve Bank, was discussing the possible consequences of two actions being contemplated by the U.S. Congress at the time: first, the ending of the tax cuts enacted during George W. Bush's presidency, and second, the triggering of the large spending cuts in the so-called 'sequester'. Bernanke was, quite understandably, concerned that going over the cliff -i.e., allowing the tax rates to rise and the spending cuts to take effect- would result in a great deal of liquidity being rapidly taken out of the U.S. economy while it was still weak. But instead of explaining this concern clearly, he exploited the public's confusion about economics in general, and deficits in particular, to give the false impression that going over the cliff would significantly raise the deficit. Bernanke's remarks thus "eroded democratic ideals" (85) while appearing to uphold them, by playing on fear of deficits and reinforcing false beliefs about the economy. This, in turn, made future rational debate on these topics that much harder to achieve. Or so Stanley argues.

(Stanley's discussion of this, and other, examples raises a worry about what precisely he means by "embodiment" of ideals. Presumably, an intention to uphold certain ideals, or even to appear as though one is upholding them, can't be required; Bernanke quite plausibly had no specific intentions about democratic ideals at all when making his comments. What then makes it the case that Bernanke was embodying these ideals? Is the fact that he was making a contribution to public discourse in his official governmental role enough? Did the content of his contribution matter? Would an ordinary citizen's contribution to public discourse in a democracy also so count?)

The Bernanke example is also meant to illustrate the role that flawed ideological beliefs play in enabling propaganda. For Stanley, ideological beliefs in general are beliefs that are resistant to rational revision in response to evidence (178-179). But he doesn't think that all such beliefs are epistemologically defective; some ideological beliefs can even constitute knowledge. Flawed ideological beliefs, in Stanley's sense, are epistemologically defective, in that their presence "hinders the acquisition of knowledge" (199). Opportunistic fear-mongering about deficits by both major political parties in the U.S. has given rise to flawed ideological beliefs about deficits. And those are the beliefs, Stanley suggests, that allow Bernanke's talk of fiscal cliffs to do its work.

In the final chapters of the book (particularly Chapters 5 and 6), Stanley draws together the elements described thus far to argue for a further noteworthy conclusion,

5 Stanley also discusses this example in an earlier piece (Stanley 2013). I'll return to this example repeatedly throughout this paper. I focus on this example largely because Stanley discusses it in quite a bit of detail. 
namely, that inequalities — specifically, "substantive material, social, and economic inequalities” (216) - are democratically problematic. That's because these inequalities tend to enable certain flawed ideological beliefs to flourish, particularly those beliefs that are needed to make the inequalities appear legitimate. These flawed ideological beliefs, in turn, allow harmful propaganda to be effective. And harmful propaganda is antithetical to the kind of rational debate that is crucial for a democracy. So, the argument concludes, inequalities of these kinds are bad for democratic societies. Call this Stanley's 'inequality argument' (see 180-181 for a useful overview).

There is much to say about this intriguing argument, but I won't attempt an in-depth assessment here. Rather, I'll close my overview by raising a pair of (related) questions about the overall dialectic of the book.

To begin, recall that on Stanley's view, harmful propaganda both exploits and strengthens flawed ideologies. That raises the first question: what does it mean to say that propaganda strengthens flawed ideologies? Stanley's discussion helps to illuminate how propaganda exploits flawed ideologies. But less is said about how it strengthens these ideologies.

In his discussion of the Bernanke case, for instance, Stanley writes that Bernanke's use of 'fiscal cliff "reinforced the public's false beliefs about economics" (85). He adds:

[In relying upon flawed ideological beliefs about the economy] Bernanke thus set the stage for the subsequent irrational public deliberation that preceded the debt ceiling crisis in 2013. ... Flawed ideological beliefs corrode rational debate. In a healthy democracy, the goal of a public official should be to dissolve them, rather than rely on them. Relying upon them only strengthens them and makes them much more problematic barriers in subsequent debate (86, emphasis added).

This passage suggests a very close connection between exploiting certain beliefs, and strengthening them: perhaps the thought is that whenever flawed ideological beliefs are exploited - especially by those in positions of authority - they are thereby strengthened. But that seems too strong a link. Suppose a professor knows that her students believe she never grants extensions; she says to them, "Final papers are due on April 30", knowing that she can exploit those false beliefs to get papers in by that date and no later. It's hard to see in what sense this exploitation can be said to strengthen the relevant beliefs. The professor's behavior provides no new evidence in favor of those beliefs; nor does it make it harder for the students to consider alternative possibilities than previously. Instead, the exploitation here largely leaves those beliefs as before. Whatever strengthening amounts to, then, it should not be tied too closely to exploitation; not every instance of exploiting a belief strengthens it in any interesting sense. ${ }^{6}$

My second question focuses on Stanley's inequality argument. The question is this: how crucial is propaganda to this argument? Recall that that argument is intended to establish that inequalities of many kinds are democratically problematic. And it does so by

6 It's compatible with what I've just said that Bernanke missed an important opportunity to clear up public confusion, and in so doing, failed in his role as a public official. Stanley points to this failure in the passage quoted above. But even if that's right, that only suggests that Bernanke is personally criticizable, perhaps even blameworthy, for his contribution. Not much follows, I think, about whether his alleged failure strengthened the ideologies in question. 
pointing to a link between those inequalities and flawed ideological beliefs, and a further link between those beliefs and propaganda. But we might ask whether Stanley has the resources to make a simpler argument for the same conclusion, one that doesn't rely on the second link all. According to this simpler argument, inequalities are democratically problematic because the flawed ideological beliefs they enable are themselves democratically problematic. After all, for Stanley, flawed ideological beliefs interfere with the acquisition of knowledge, including knowledge about the injustices being committed in our communities. Such beliefs keep us from understanding the true nature of our social reality, and relatedly, from correctly identifying our own interests. They therefore pose a serious challenge for democratic deliberation, and so, are bad for democratic societies.

The argumentative strategy outlined above aims to show that flawed ideological beliefs are democratically problematic without ever appealing to propaganda. Of course, I've only sketched that strategy here; many details would have to be filled in to make the argument work. But as I understand him, Stanley is committed to everything said above about how flawed ideological beliefs work, and defends these commitments in the final chapters of his book. That means that he is in a position to offer the simpler argument described above, which makes no claims about the nature of propaganda. To put it another way, Stanley has the resources to construct an argument that's at least as strong as his (original) inequality argument, without drawing on any of the material in the four chapters of his book.

The two questions I've raised are related in that an answer to the first question may help shed light on the second. That is, a fuller account of how propaganda strengthens flawed ideologies (as called for by the first question) may help explain why propaganda makes those ideologies even more democratically problematic than they would be otherwise. And that, in turn, may explain why the simpler argument sketched above - even if sound - fails to capture the full extent of the challenge posed by flawed ideologies to democratic societies.

This completes my overview of Stanley's arguments. As I mentioned in the Introduction, this is by no means comprehensive; but it should suffice to make clear the sheer ambition of Stanley's work. In the remainder of the paper, I'll home in on some parts of Stanley's account, beginning with his view of what propaganda is.

\section{Propaganda and incompetence}

Stanley's conception of propaganda - of both the supporting and undermining kinds - is broad in at least two ways: on his view, propaganda need neither be false nor insincerely uttered (Chapter 2). To illustrate this point, he imagines a non-Muslim politician in the U.S. saying to his audience, "there are Muslims among us" (42). The politician, we can stipulate, intends this as a kind of warning, and means to stoke fear of Muslim Americans. But what he says here is true, and may be sincerely uttered. The politician may even believe that fear is a fitting reaction to Muslim Americans and other Muslims in the U.S. Nevertheless, Stanley thinks that this utterance should count as propaganda. If so, the falsity and insincerity conditions on propaganda must be jettisoned.

One response to this argument would be to insist that, while propaganda doesn't have to say something false, it must at least communicate something false. That might give us a modified falsity condition: in order for something to be propaganda, it must convey some- 
thing false, whether explicitly or not. ${ }^{7}$ Stanley considers this response, and offers several reasons to reject it (42-43). Among these is the following point:

$[T]$ here is a perfectly natural way of thinking of the effects of propaganda according to which it can involve the expression of truths and the communication of emotions. If emotions are not true or false, then propaganda need not be false. In fact, the case of "there are Muslims among us," used to elicit a fear of Muslims, is a case of exactly this structure (43).

Here, as elsewhere, Stanley emphasizes the role of emotions in effective propaganda. A defender of the spirit (if not the letter) of the falsity condition can still try to salvage something here, perhaps by noting that emotions can be fitting or unfitting. But Stanley is surely right to emphasize that the conveying of false contents needn't play any crucial role in propaganda.

So far, so good. But one consequence of giving up both the falsity and insincerity conditions on propaganda is that quite a lot may end up counting as propaganda. In particular, contributions to public discourse that are sincerely intended to uphold political, scientific, or other ideals, but that end up backfiring against those ideals - perhaps due to the incompetence of the contributor - will sometimes qualify as undermining propaganda.

Here's one (somewhat fictional) example to illustrate this point. Imagine a politician who genuinely wishes to use the best social scientific research to inform his political views, but happens to be not very good at deciphering said research. This politician reads an influential economist's report that nearly $98 \%$ of the net increase in wages and benefits due to immigration goes to the immigrants themselves (Yglesias 2015, reporting on the work of "immigration-skeptical" economist George Borjas). Failing to recognize that this figure implies that immigration increases wages and benefits for non-immigrants as well, though by a smaller margin, the politician proceeds to use this research to argue for a drastic reduction in immigration ("Economists have shown that immigration takes away wages from you, the American worker..."). The view begins to take hold, and becomes an increasingly influential talking point against the free flow of immigration. Those who understand what is happening come to conclude that social scientific research can be twisted to serve any end whatsoever. Through his incompetence, the politician thus ends up subverting the very ideals - about the value of scientific research to policymaking - that he intended to uphold. Call this the 'incompetent politician' case.

This case is one example of bad political argumentation; but of course, it's not hard to come up with many more. But when bad arguments end up rebounding against the sometimes worthy ideals they are meant to serve, they look like undermining propaganda in Stanley's sense. (In fact, the same can be said about good political argumentation, but I won't pursue that point here.)

Interestingly, Stanley's Bernanke case may give us a further example of political argumentation backfiring. In his discussion of that case, Stanley supposes that Bernanke was "well aware that his warning would be misunderstood [as a warning about a potentially catastrophic increase to the deficit], and that the misunderstanding would lead to its effective-

7 An analogous move can be made with respect to sincerity as well, though in my view, the move is (even) less plausible in the latter case. 
ness" (84). But as Stanley also admits, that's mere speculation. ${ }^{8}$ A different reading of the case would see it as one of incompetence: Bernanke used a phrase that confused his public, contrary to his intentions. Understood this way, this is an example in which Bernanke embodies democratic ideals, just as Stanley suggests, but what he says (accidentally) ends up backfiring against those ideals.

As mentioned earlier, it may be that several distinct accounts of propaganda are viable; perhaps different accounts will be needed to do different kinds of theoretical work. Nevertheless, any account of propaganda that counts all instances of political discourse eroding the ideals they embody via the incompetence of the contributor, or the audience, or both, will surely end up making that category unacceptably broad. For one thing, such a broad account would blur important distinctions about what needs to be done to ameliorate the effects of propaganda, since eroding of ideals via incompetence presumably calls for rather different remedies than eroding of ideals via flawed ideologies.

Let me briefly address two possible responses to what I've argued thus far. The first response seeks to exclude examples like the incompetent politician case on the grounds that they don't involve flawed ideologies. According to this response, even if the politician's contribution does undermine the ideals in question, that undermining doesn't happen via the exploitation of flawed ideological beliefs. So, according to this response, that isn't an instance of (undermining) propaganda. (By contrast, since the Bernanke case does involve flawed ideological beliefs, that would still count as propaganda.)

But this response is not successful, for two reasons. First, note that Stanley's characterization of the two kinds of propaganda (quoted in $\$ 2$ ) doesn't include any mention of flawed ideological beliefs. That is, as I understand him, Stanley is committed to the view that the operation of propaganda will typically involve flawed ideologies, but this isn't definitional; for him, it is not a necessary condition for something's being propaganda that it operate in this way. Second, and more importantly, the response described above only succeeds in pushing the issue further back. Recall that for Stanley, flawed ideological beliefs are ones that are resistant to rational revision, and that hinder the acquisition of knowledge. But one significant source of resistance to rational revision is sheer incompetence: if, for example, an agent has difficulty with numerical reasoning, his numerical beliefs may be highly resistant to rational revision, due to his incompetence in the domain. And these beliefs may well prevent him from coming to know things. But we would not want to say that these are flawed ideological beliefs. So the issue raised by the incompetent politician case remains to be solved.

A different response to my argument focuses on the 'tends to' locution that appears in both of Stanley's notions of propaganda. To say that something, $X$, tends to produce some effect $E$ need not be to say that $X$ always produces $E$; it may be that $X$ only produces $E$ when certain background conditions $C$ are in place. And once that has been noted, the theorist has room to specify which background conditions are relevant to the analysis. With respect to the issue at hand, we can agree that contributions to public discourse can erode ideals either due to the incompetence of the contributor (and/or audience), or due to their flawed ideological beliefs; but, according to the current response, the former is a more ac-

8 Further, given Stanley's own rejection of the insincerity condition on propaganda, it is not clear why Bernanke's beliefs/intentions should matter. 
cidental, or shallower, feature of reality, than the latter. To put it another way, erosion of ideals due to flawed ideological beliefs will persist across a wider range of background conditions - be harder to remedy, perhaps - than erosion of ideals due to incompetence. And that difference can be marked in our understanding of the 'tends to' locution, and so, in our understanding of propaganda.?

I think this response is much harder to counter than the previous one. And it's not one that I can do justice to here. But very briefly, let me say that I'm not optimistic about the idea that incompetence is a less robust, or shallower, feature of reality than flawed ideology. At the very least, I suspect that the former is, in practice, no easier to ameliorate than the latter. But this is, in the end, an empirical issue, and a tricky one at that, for it will often be hard to tell whether it is incompetence, flawed ideology, or some mutually reinforcing combination of the two that is at work in a given case. As such, this issue is not something that can be settled here.

\section{Non-rational means}

In this section, I'll explore a further response to the worries raised in the previous one. But as I'll also show, the view explored here has merit regardless of whether it succeeds in resolving those particular worries.

Recall that I argued in the last section that Stanley's account over-generalizes, for examples like the incompetent politician case should not count as (undermining) propaganda. One way to get the right results in such cases would be to revise Stanley's characterization as follows:

Undermining Propaganda (Revised): A contribution to public discourse that is presented as an embodiment of certain ideals, yet is of a kind that tends to erode those very ideals by either emotional or other nonrational means.

The idea here is that undermining propaganda not only subverts certain ideals, as in Stanley's original characterization, but that it does so in a particular way, i.e., via non-rational means. The revision brings undermining propaganda more in line with Stanley's conception of supporting propaganda:

Supporting Propaganda: A contribution to public discourse that is presented as an embodiment of certain ideals, yet is of a kind that tends to increase the realization of those very ideals by either emotional or other nonrational means (53).

The resulting view is perhaps closer to the classical sense of propaganda (discussed in \$2) -according to which propaganda is "manipulation of the rational will to close off debate" (48, emphasis removed) - than Stanley's own account is.

The revised proposal is in keeping with much of what Stanley says about propaganda generally: for example, that it "short-circuits" rationality (11), that it "bypasses rational de-

9 This response is based on a suggestion made by Stanley in his remarks at a session on his book at the Pacific APA. But I may not be fully capturing that suggestion here. 
liberation" (12), that it operates to "cut off rational deliberation and discussion", characteristically by "overwhelm[ing] affective states" (47), that it involves "a kind of manipulation of rational beings toward an end without engaging their rational will" (58), and so on. These characterizations are not equivalent — short-circuiting something is arguably different from bypassing it altogether, for instance- but they all point towards the thought that propaganda does its work through non-rational means.

This line of thinking also fits well with the examples of propaganda discussed already. Consider first the (fictional) example of the politician saying, "there are Muslims among us." As Stanley suggests, that utterance can be thought of as playing upon (irrational) fear of Muslims, exploiting that fear to move the audience to action, or at least to the voting booth. Much the same can be said about the Bernanke case. There too the speech plays upon (irrational) fear, or perhaps anxiety, this time about deficits. In both cases, the effectiveness of the propaganda depends upon the presence of that fear and anxiety.

The revision suggested above has further advantages. For one thing, it does away with the (otherwise puzzling) asymmetry between Stanley's two notions of propaganda. And it can capture why the incompetent politician's contribution doesn't count as propaganda. The politician puts forth an argument for his conclusion, namely, that immigration should be further restricted. But because he has misunderstood the underlying research, it's a terrible argument. Nevertheless, the politician is genuinely attempting to rationally persuade his audience. And that's also how his contribution is regarded by his audience. Therefore, there is a clear sense in which he is employing rational means, though in a sub-optimal way.

At the same time, the suggested revision would bring some costs for Stanley, for it would exclude some of his examples of propaganda. Consider, for instance, climate change denial. Stanley suggests that some deniers present themselves as exemplifying the highest ideals of scientific objectivity, while undermining those very ideals by exaggerating the uncertainty involved in climate science, cherrypicking certain bits of evidence and ignoring others, and so on (60). While this is undoubtedly problematic, some of this kind of denial doesn't seek to bypass rational deliberation, or to act via non-rational means more generally. Rather, it seeks to influence the outputs of rational deliberation by emphasizing certain parts of the evidence, and occluding other parts. As such, this kind of climate change denial doesn't count as undermining propaganda, according to the revision under consideration here.

This is the right result. One way to see this is to note the similarity between this kind of climate change denial and the incompetent politician case discussed earlier. The main difference between the cases is the presence (or not) of deceptive intentions on the part of the speaker(s). But Stanley's original characterization of propaganda, as well as his arguments against the falsity and insincerity conditions (discussed in \$3), suggest that the presence of intentions of this type doesn't matter to whether some contribution is propaganda. That seems to me an attractive view. In keeping with that view, we should treat this kind of denial like the incompetent politician's contribution, i.e., as not propaganda.

(Of course, plenty of climate change denial would still count as undermining propaganda even on the revised proposal. Insofar as much climate change denial erodes scientific ideals by playing on group identity, particularly strong affiliation with a political party, it exploits flawed ideology in just the way that Stanley describes (181-183).)

To make the revised proposal work - as well as to flesh out Stanley's own account of supporting propaganda - more needs to be said about what counts as "emotional or other nonrational means" for these purposes. To demonstrate why, I'll look at a further pair of 
cases, in which contributions to public discourse are designed to appeal to our affective states. (Both examples are candidates for being supporting propaganda; but I assume that, in light of the revision, the "emotional or other nonrational means" qualifier is to be understood the same way in both notions.)

First, consider an advertising campaign that seeks to deter drinking and driving by drawing attention to the steep human cost of this behavior. An ad in this campaign shows a mother picking the broken body of her young daughter off a road, following a crash caused by a drunk driver. ${ }^{10}$ Second, consider newspaper photographs of victims in the aftermath of a terrorist action, such as the photograph of the two bloodied women survivors that circulated widely after the recent bombing in Brussels (Khomami 2016).

Images like these do two things. First, they invite viewers to feel empathy for the victims, to share in their suffering. But equally, they invite viewers to feel contempt for the perpetrators of the suffering, to regard them as something like moral monsters. (This is particularly clear in many of the ads in the 'Everyone hurts' campaign. Several of these depict the drivers as selfish and thoughtless, caring more about their own fleeting pleasures than the wellbeing of others (TACVictoria 2009).) By doing these things, these images seek to motivate us to be different from the perpetrators, and perhaps to share in the effort of bringing the perpetrators to justice.

In light of these observations, we can ask: do these images count as (supporting) propaganda, on Stanley's view? They are clearly contributions to public discourse that attempt to realize certain ideals, e.g., ideals of health, safety, political solidarity, and so on; and they do so by appealing strongly to our emotions. In fact, they arguably aim to overwhelm us emotionally, and thus motivate us to act while "bypassing" rational deliberation. So that's some reason to think they should count as propaganda.

At the same time, as Stanley recognizes, not every appeal to emotions is non-rational. Emotions can be perfectly rational: for example, it is be rational for me to be afraid of snakes, and it is also rational for me to feel affection for the city of San Francisco. Along these lines, Stanley writes:

Propaganda is not simply closing off rational debate by appeal to emotion; often, emotions are rational and track reasons. It rather involves closing off debate by "emotions detached from their ideas." ... [P] ropaganda closes off debate by bypassing the rational will. It makes the state move as one, stirred by emotions that far surpass the evidence for their intensity (48, emphasis added in final sentence). ${ }^{11}$

Here's a view suggested by this passage: we could say that a contribution to public discourse that acts via emotional means qualifies as propaganda only if the emotions it exploits/

10 The image I have in mind is part of the 'Everybody hurts' advertising campaign from the Transport Accident Commission (TAC) of the state of Victoria in Australia. That image, among many others, is included in their 20 year campaign retrospective (TACVictoria 2009). This campaign produced a series of particularly emotionally wrenching images, but broadly similar campaigns have been mounted by other sources.

${ }^{11}$ In this passage, Stanley is discussing the classical sense of propaganda, which (as mentioned in \$2), is distinct from his preferred view. But what he says here suggests resources for interpreting both his view of supporting propaganda and the revised proposal for undermining propaganda. 
evokes are stronger than what is warranted by the facts. (I say 'the facts' rather than 'the evidence' so as to avoid questions about whose evidence.) On this view, whether the images described earlier constitute propaganda depends on whether the contempt they play upon fits the facts; if that contempt is warranted, then the images are not propaganda. Similarly, whether Bernanke's remarks about the fiscal cliff constitute propaganda depends on whether the fear (of deficits) they play upon is warranted. If, as some economists have argued, that fear is significantly overblown, those remarks may well count as propaganda, just as Stanley suggests.

Of course, whether some emotions do fit (or fail to fit) the facts is often a really hard question. So the resulting account of propaganda won't always be easy to apply. And there are alternate ways of interpreting the "emotions or other nonrational means" qualifier that are also worth examining. But some such interpretation will be needed to flesh out both Stanley's view of supporting propaganda, as well as my revised proposal regarding undermining propaganda.

\section{Civic rhetoric}

Having now spent some time on Stanley's conception of propaganda, I turn in this final section to his view of propaganda that is democratically acceptable, i.e., of civic rhetoric. Merely aiming at - or even achieving — a praiseworthy goal is not enough to make propaganda democratically legitimate, for Stanley: the Bernanke case, for instance, is one in which the propagandist has laudable aims, but the propaganda still undermines democratic ideals in an unacceptable way.

To get at Stanley's view of when propaganda does constitute civic rhetoric, it will help to begin with his discussion of the (Rawlsian) norm of reasonableness, understood as an ideal for public discourse within a democracy (Chapters 3-4). To be reasonable in this sense "is to take one's proposals to be accountable to everyone in the community" (108). Since others in the community may have very different perspectives from one's own, this will involve taking into account those differing perspectives. Stanley argues that empathy, or "the capacity to put oneself in another's shoes" (108, emphasis removed), is crucial to taking others' perspectives into account, and so, to the realization of reasonableness.

Of course, public discourse in most actual democracies is not fully reasonable in this sense. Instead, in such societies, the perspectives of some have been systematically excluded, to the point of being rendered invisible to those in power. As a result, the powerful don't take themselves to be accountable to the excluded members. To rectify this, Stanley writes:

What is required is extending the domain of cognitive empathy to include those citizens, and there is no obvious cogent argument, from the perspective of just those citizens who are included in the sphere of liberal democratic ideals, to do so (116).

Where rational persuasion will not work, propaganda becomes the only means for bringing those whose perspectives have previously been excluded into the political community, and thereby increasing the reasonableness of the ensuing debate. This is what civic rhetoric does. Stanley points to passages from Fannie Barrier Williams' essay “The woman’s part in 
a man's business" (112-113) and W.E.B. Du Bois' The Souls of Black Folk (116) as examples of propaganda of this kind.

In my view, Stanley is right to emphasize the dangers of propaganda, even when used for worthy ends. But the view sketched above sets a very high bar for civic rhetoric, in two ways. First, it suggests that propaganda is democratically acceptable only when other (rational) means for repairing flawed ideologies — specifically, ideologies that unfairly exclude some from the political community - are doomed to failure. Second, it also suggests that civic rhetoric must extend empathy to those whose perspectives had previously been excluded; at the very least, it should never seek to decrease empathy for others in our political community. As I'll argue below, both claims are questionable.

To see why, consider another series of images, this time those used in the 'Don't be that guy' campaign against sexual assault that began in Canada (Battered Women's Support Services n.d., Women Against Violence Against Women n.d.). Like some others, this campaign seeks to educate its audience about what constitutes sexual assault. What's distinctive about this particular campaign, though, is that its primary target audience is men, specifically, young men. As the campaign founders explain:

We are sending a visual message to men between the ages of 18 and 25, graphically demonstrating their role in ending alcohol facilitated sexual assaults. Don't Be That Guy shifts the emphasis to men to take responsibility for their behaviour. Studies involving 18-25 year old men revealed that 48 per cent of the men did not consider it rape if a woman is too drunk to know what is going on (Battered Women's Support Services n.d.).

One image in this campaign depicts an intoxicated and stumbling woman being helped into a car by a man; at the bottom of the image we see the tagline, 'Just because you help her home... doesn't mean you get to help yourself.'

The 'Don't be that guy' campaign does two main things. First, it argues that having sex with someone who is too drunk to consent is unambiguously sexual assault, that there is no gray area on that question. Second, the campaign also tries to attach a kind of stigma to anyone who would have sex with a drunk woman; that's the point of the 'that guy' label.

Let's assume here, as I think is plausible, that the images in this campaign are propaganda. ${ }^{12}$ Given that, they are clearly democratically acceptable propaganda. Indeed, they serve a crucial function, insofar as they educate us about the seriousness of sexual assault, that it cannot be dismissed as merely a 'regrettable' mistake that young people are prone to make.

Nevertheless, these images fail to satisfy either of Stanley's conditions on civic rhetoric mentioned above. First, it's certainly possible that other (rational) means for repairing the flawed ideologies in question -ones which fail to take sexual assault seriously, that fail to respect the perspectives of survivors - would succeed, at least eventually. We have, after all, made some progress with respect to thinking, and talking, about sexual assault. But regardless of that possibility, the 'Don't be that guy' campaign seems also worth trying. The problem of sexual assault is urgent enough, and multifaceted enough, to justify multiple approaches, including this one. The availability of other (rational) means for repairing the ideologies in question seems irrelevant to the democratic acceptability of this campaign.

12 The points I will make below about this campaign also apply, mutatis mutandis, to the 'Everybody hurts' campaign discussed in the previous section. 
Second, and more importantly, the 'Don't be that guy campaign' not only fails to extend empathy to its targets, namely, perpetrators of sexual assault as well as those who just don't "consider it rape if a woman is too drunk to know what is going on"; it in fact seeks to decrease our empathy for them. As mentioned above, the campaign seeks to stigmatize these individuals for their actions (or attitudes). Though this is open to interpretation, it may even urge contempt towards these individuals. Moreover, this is plausibly not an accidental feature of this campaign, for taking sexual assault as seriously as it deserves may require all of us to feel less empathy, and less respect, for those who hold the attitudes described above.

If all this is right, then the "Don't be that guy" campaign is democratically acceptable propaganda even though it fails to satisfy Stanley's conditions for civic rhetoric. That's not to say that all propaganda should be considered acceptable in a democracy as long as it has some laudable goal (or effect): a sexual assault prevention campaign that relies on widely held racist stereotypes should not be acceptable, for example. Stanley, I think, is right on this point. Rather, my argument points to the need for a middle ground between this kind of overly permissive view, and what I've described as Stanley's too high bar for civic rhetoric. What that middle ground should be I'll leave as an open question here.

\section{Conclusion}

My discussion in this paper has touched on some interesting questions raised by Stanley's provocative work; but as I suspect is clear at this point, there is a lot more to be said about all of these issues. In closing, I'll briefly emphasize one theme that has run through my discussion, namely, the importance of emotion to the success of propagandistic representations. As I've tried to bring out (and as Stanley agrees), propaganda can rely on emotions to both negative and positive effect. Further discussion of both aspects - and especially of what marks the democratically acceptable uses of propaganda- would be particularly worthwhile.

\section{REFERENCES}

Battered Women's Support Services. n.d. "The violence stops here: Don't be that guy." URL $=<$ http:// www.theviolencestopshere.ca/dbtg.php >. Accessed 1 July 2016.

Haslanger, Sally. 2006. "What good are our intuitions?: Philosophical analysis and social kinds." Aristotelian Society Supplementary Volume 80(1): 89-118. Reprinted in her 2012: 381-405.

Haslanger, Sally. 2012. Resisting Reality: Social Construction and Social Critique. Oxford: Oxford University Press.

Khomami, Nadia. 2016, 23 March. "The photograph that has come to define the horrors of the Brussels attacks." The Guardian. URL = <https://www.theguardian.com/world $/ 2016 / \mathrm{mar} / 23 /$ the-photographthat-has-come-to-define-horrors-of-brussels-attacks $>$. Accessed 1 July 2016.

Srinivasan, Amia. 2016. "Philosophy and ideology." Theoria 31(3): 371-380.

Stanley, Jason. 2013, 31 January. "Philosopher kings and fiscal cliffs." The New York Times. URL $=<$ http:// opinionator.blogs.nytimes.com/2013/01/31/philosopher-kings-and-fiscal-cliffs/>. Accessed 1 July 2016.

Stanley, Jason. 2015. How Propaganda Works. Princeton, NJ: Princeton University Press. 
Swanson, Eric. Forthcoming. "Critical notice of How Propaganda Works." Mind.

TACVictoria. 2009, 8 December. "TAC 20 year anniversary TV ad montage 'Everybody hurts'." YouTube. URL $=\langle$ https://www.youtube.com/watch?v=Z2mf8DtWWd8>. Accessed 1 July 2016.

Women Against Violence Against Women. n.d. "Don't be that guy campaign." URL $=<$ http://www. wavaw.ca/campaigns/dont-be-that-guy-campaign/>. Accessed 1 July 2016.

Yglesias, Matthew. 2015, 17 August. The most neglected fact in immigration economics. URL $=<$ http:// www.vox.com/2015/8/17/9164725/immigration-and-wages-impact $>$. Accessed 1 July 2016.

Ishani MaItra is an associate professor of philosophy at the University of Michigan at Ann Arbor. Her main areas of research interest are philosophy of language, feminist philosophy, and philosophy of law. She has published articles on silencing, subordination, the right to free speech, assertion, contextualism, testimony, and philosophical methodology.

AdDress: 2215 Angell Hall, 435 South State Street, Ann Arbor, MI 48109, USA. E-mail: imaitra@umich.edu 